\title{
Estudo comparativo da legislação vigente para aditivos em produtos lácteos no Brasil, Estados Unidos da América e Europa
}

\section{Comparative study of current legislation for additives in dairy products in Brazil, United State of America and Europe}

\author{
Maria Carolina Gonçalves Rodrigues ${ }^{1}$; Geoffroy Roger Pointer Malpass ${ }^{2}$; Mônica Hitomi \\ Okura $^{3}$; Ana Claudia Granato ${ }^{*}$ \\ ${ }^{1}$ Aluna do Programa de Mestrado Profissional em Inovação Tecnológica, Universidade Federal do \\ Triângulo Mineiro, Uberaba, Minas Gerais, Brasil. Email: mariacarolinagr@hotmail.com \\ ${ }^{2}$ Professor do Programa de Mestrado Profissional em Inovação Tecnológica, Universidade Federal do \\ Triângulo Mineiro, Uberaba, Minas Gerais, Brasil. Email: geoffroy.malpass@uftm.edu.br \\ ${ }^{3}$ Professora do Programa de Mestrado Profissional em Inovação Tecnológica, Universidade Federal do \\ Triângulo Mineiro, Uberaba, Minas Gerais, Brasil. Email: monica.okura@uftm.edu.br \\ ${ }^{4}$ Professora do Programa de Mestrado Profissional em Inovação Tecnológica, Universidade Federal do \\ Triângulo Mineiro, Uberaba, Minas Gerais, Brasil. Orcid: 0000-0001-6487-1225. Email: \\ ana.malpass@uftm.edu.br
}

RESUMO: Para disponibilizar alimentos saudáveis e seguros para toda a população, é necessário um rigoroso cumprimento das legislações e dos parâmetros de qualidade que regem o setor de produtos lácteos, independente do país. O objetivo deste estudo foi analisar comparativamente as legislações vigentes no Brasil, Estados Unidos da América e Europa, para leite UHT, queijo muçarela e iogurte batido com relação a inclusão de aditivos nesses produtos. Nos Estados Unidos e Europa, são realizadas políticas focadas no crescimento e expansão dos negócios, visto que o setor de leite e derivados já é uma área econômica fortalecida e consolidada. Já o Brasil ainda encontra-se em fase de ajustes e estruturação do setor. Por isso, é imprescindível que o Brasil possa atuar em planos de melhoria contínua para que o mercado de leites e derivados brasileiro seja referência em qualidade e segurança alimentar.

Palavras-chave: Aditivos químicos; Leite UHT; Muçarela; logurte.

ABSTRACT: In order to provide healthy and safe food for, strict compliance with the legislation and quality standards governing the dairy sector is required, regardless of the country. The objective of this study was to analyze, comparatively, the laws in force in Brazil, the United States and Europe, for UHT milk, mozzarella cheese and beaten yogurt in relation to the inclusion of additives in these products. In the United States of America and Europe, policies are focused on growth and business expansion, as the dairy and derivatives sector is already a consolidated economic area. Brazil is still in the process of adjusting and structuring the sector. Therefore, it is imperative that Brazil acts on plans for continuous improvement so that the Brazilian milk and dairy market is a reference in food quality and safety.

Keywords: Chemical additives; Mozzarella; UHT milk; Yogurt. 


\section{INTRODUÇÃO}

O setor agroindustrial de produtos lácteos é um setor da economia muito importante no Brasil e no mundo. Dados revelam que, no Brasil, Estados Unidos da América e Europa o consumo de leite foi de 61,3; 71,6 e 62,4 litros per capta em 2014, respectivamente (CANADIAN DAIRY INFORMATION CENTRE, 2016). O queijo tipo muçarela é o mais consumido no mundo e tem um consumo per capta de cerca de 3,74; 15,18 e 15,65 kg, no Brasil, Estados Unidos e Europa, respectivamente. Já a quantidade de pessoas que consomem iogurte, ao menos uma vez ao dia, no Brasil é aproximadamente, $27 \%$, sendo que este dado é um pouco maior que nos Estados Unidos da América, cerca de $20 \%$ e significativamente menor que em alguns países da Europa, que podem chegar até $57 \%$ (DSM FOOD SPECIALTIES, s.d.).

Com o estilo de vida moderna, a utilização de produtos que apresentam aditivos adicionados tornou-se algo corriqueiro. Os aditivos são substâncias adicionadas aos alimentos que podem ser naturais ou artificiais e, de acordo com a função desempenhada, podem ser classificados como: agente de massa, antiespumante, antiumectante, antioxidante, corante, conservante, edulcorante, espessantes, geleificantes, estabilizante, aromatizante, umectante, regulador de acidez, acidulante, emulsificante, melhorador de farinha, realçador de sabor, glaceante, agente de firmeza, sequestrante, estabilizante de cor e espumante (BRASIL, 1997). O uso de aditivos contribui para a conservação e extensão da vida de prateleira, a cadeia logística de comercialização dos produtos e as necessidades constantes de inovação. Estes fatores favorecem a utilização dos aditivos, porém a utilização destas substâncias deve ser orientada pela legislação para evitar riscos à saúde dos consumidores (AUN et.al, 2011). A Portaria $n^{\circ}$ 540, 27 de outubro de 1997 da Secretaria de Vigilância Sanitária/ Ministério da Saúde (ANVISA, 1997), discorre sobre a empregabilidade dos aditivos.

No Brasil, a Instrução Normativa 51/2002, do Ministério da Agricultura Pecuária e Abastecimento (MAPA, 2002), informa os Regulamentos Técnicos de Qualidade e Identidade do Leite tipo A, B, Pasteurizado, Cru Refrigerado e Transporte a granel. Entretanto, a Portaria 146 de 07 de Março de 1996 (MAPA, 1996) e o Portaria 370/1997 (MAPA, 1997), do Ministério da Agricultura Pecuária e Abastecimento, informa os Regulamentos Técnicos de Qualidade e Identidade do Leite UHT (Ultra High Temperature). Com relação a queijos a Portaria n 146, de 7 de março de 1996 (MAPA, 1996) também trata do regulamento técnico e de qualidade desses. Já a Instrução Normativa $n^{\circ} 46$, de 23 de setembro de 2007 (MAPA, 2007), define o iogurte batido.

Alguns aditivos apesar de sua funcionalidade tecnológica podem desencadear riscos à saúde dos consumidores e, por isso, não são utilizados em alguns países. Pereira, Moura e Constant (2008) informam que alguns aditivos, dentre eles: tartrazina, sulfitos, glutamato monossódico e citrato de sódio merecem atenção especial, devido ao fato de provocarem desconfortos aos consumidores, como: urticárias, alergias, dores de cabeça e vermelhidão na pele.

Com menor disponibilidade de tempo para realizar suas compras, os consumidores optam por adquirir produtos que tenham um prazo de validade longo. O termo vida de prateleira ou shelf life, está intimamente relacionado com a manutenção da qualidade do alimento durante o período de estocagem. De acordo com a Resolução RDC $n^{\circ}$ 259/2002 (ANVISA, 2002) é obrigatório informar aos consumidores nos rótulos das embalagens o item referente à data de validade. Ou seja, o shelf file de um determinado produto é importante para o consumidor, pois determina o período em que o alimento é seguro para o consumo. Para o produtor este tempo relata aspectos sobre a redução e/ou perda da 
qualidade desejável para o produto e o distribuidor consegue se organizar para realizar o armazenamento e escoamento da produção para os centros varejistas (Grizotto et.al., 2006).

Desta forma, esse trabalho tem como objetivo comparar a legislação vigente no Brasil, Estados Unidos da América e Europa para a adição de ativos químicos em produtos lácteos (leite UHT, queijo tipo muçarela e iogurte batido) com o objetivo de propor melhorias na legislação brasileira para esses produtos podendo torna-los consumidores mais exigentes, nacional e internacionalmente.

\section{METODOLOGIA}

Foram realizadas buscas das legislações do Brasil, Estados Unidos da América e Europa sobre a utilização de aditivos em leite UHT (Ultra High Temperature), queijo tipo muçarela e iogurte batido. Essas buscas foram realizadas nos órgãos reguladores de cada país que podem ser vistos na tabela 1. Os dados foram confrontados com as informações contidas no Codex Alimentarius. Além disso, foram utilizados artigos científicos a fim de encontrar conteúdos referentes à segurança alimentar, produtos lácteos, aditivos e processamento de iogurtes, leite e queijos, as substâncias permitidas na industrialização de lácteos e os impactos na qualidade do produto final.

Tabela 1. Orgãos reguladores para produtos lácteos no Brasil, Europa e ESTADOS UNIDOS A AMÉRICA.

\begin{tabular}{c|c|c}
\hline Local & Órgão & Sites \\
\hline Brasil & $\begin{array}{c}\text { ANVISA } \\
\text { MAPA } \\
\text { INMETRO }\end{array}$ & $\frac{\text { www.anvisa.gov.br }}{\text { http://www.agricultura.gov.br/legislacao }}$ \\
$\begin{array}{c}\text { Estados Unidos da } \\
\text { América }\end{array}$ & FDA & http://www.inmetro.gov.br/ \\
Europa & USDA & http://www.usda.gov/wps/portal/usda/usdahome \\
& $\begin{array}{c}\text { EFSA } \\
\text { European } \\
\text { Comission } \\
\text { Foods } \\
\text { Codex }\end{array}$ & http://ec.europa.eu/food/index_en.htm \\
Alimentarius & http://www.codexalimentarius.org/ \\
\hline
\end{tabular}

As legislações foram analisadas com relação à inclusão de aditivos, foram analisados os aditivos permitidos em cada uma das categorias estudadas e se os mesmos estavam em concordância sobre a quantidade e tipos de substâncias autorizadas pelo Codex Alimentarius. Desta forma, foram avaliadas quais localidades tinham o hábito de empregar mais aditivos e identificar os possíveis motivos destas práticas. Diante desta realidade, foram apresentadas possibilidades de adequação no processamento para que os produtos pudessem atender as necessidades dos clientes que visam uma alimentação com teor reduzido de substâncias artificiais. 


\section{RESULTADOS E DISCUSSÃO}

\section{Aditivos em leite de vaca}

Os aditivos permitidos para o leite UHT, no Brasil, estão expressos na tabela 2. A Resolução 135/96 do Mercado Comum do Sul (MERCOSUL, 1997) aprovou a utilização do citrato de sódio no leite UHT, o qual foi incluído por meio da Portaria $n^{\circ} 370$ de 04 de setembro de 1997 do MAPA. O leite UHT não possui conservante, visto que os estabilizantes não têm a característica de promover a conservação do produto, esta é garantida mediante a utilização do processo UHT associado ao envase asséptico, segundo os relatos da Associação Brasileira das Indústrias de Leite Longa Vida (ABLV, 2008; DOMARESKI et.al 2010).

Os aditivos listados na tabela 2 são utilizados para melhorar e garantir a qualidade do produto final. Estes estabilizantes têm como característica manter a uniformidade do leite, pois durante o processo de UHT pode ocorrer a sedimentação das proteínas, proporcionando uma desestabilização destes componentes. Tal ocorrência favorece a rejeição dos consumidores pelo produto por conta da descaracterização causada, visto que os sólidos do leite podem se depositar e comprometer a integridade do produto (ALVES, 2014; RODRIGUES, 2012). Ressalta-se que o citrato de sódio está presente no leite e que a utilização deste aditivo está em concordância com os órgãos internacionais de regulamentação, como Codex e o International Dairy Federation (IDF) (GIESEL,2009; ABLV, 2008).

Tabela 2. Quantidade máxima de Aditivos para leite UHT (mg/L) permitidos no Brasil e na Europa.

\begin{tabular}{|c|c|c|c|c|c|}
\hline \multicolumn{3}{|c|}{ Brasil } & \multicolumn{3}{|c|}{ Europa } \\
\hline Estabilizantes & $\begin{array}{l}\text { Quantidade } \\
\text { (máxima) }\end{array}$ & INS & Estabilizantes & $\begin{array}{c}\text { Quantidade } \\
\text { (máxima) }\end{array}$ & Código \\
\hline $\begin{array}{l}\text { Sódio (mono } \\
\text { fosfato) }\end{array}$ & $\begin{array}{c}\mathrm{g} / \mathrm{L} \\
\text { expresso em } \\
\mathrm{P}_{2} \mathrm{O}_{5}\end{array}$ & 339 (i) & $\begin{array}{l}\text { Polifosfatos, di } \\
\text { e tri fosfato, } \\
\text { ácido fosfórico }\end{array}$ & $\begin{array}{c}1 \mathrm{~g} / \mathrm{L} \text { expresso } \\
\text { em } \mathrm{P}_{2} \mathrm{O}_{5}\end{array}$ & $\begin{array}{c}\text { E 338 - 341, } \\
\text { E 343, E450- } \\
452 .\end{array}$ \\
\hline Sódio (difosfato) & $\begin{array}{c}1 \mathrm{~g} / \mathrm{L} \\
\text { expresso em } \\
\mathrm{P}_{2} \mathrm{O}_{5}\end{array}$ & 339(ii) & $\begin{array}{l}\text { Citrato de } \\
\text { sódio }\end{array}$ & $4 \mathrm{~g} / \mathrm{L}$ & E331 \\
\hline Sódio (trifosfato) & $\begin{array}{c}1 \mathrm{~g} / 1 \mathrm{~L} \\
\text { expresso em } \\
\mathrm{P}_{2} \mathrm{O}_{5}\end{array}$ & 339(iii) & & & \\
\hline Citrato de sódio & $1 \mathrm{~g} / \mathrm{L}$ & 331(iii) & & & \\
\hline
\end{tabular}

Legenda: INS - International Numbering System

Nos Estados Unidos da América, o relatório publicado em 24 de outubro de 2012 pelo USDA (USDA, 2012) estabelece novos padrões para o leite de vaca. Neste documento fica estabelecido que o leite de vaca deve ser livre de agentes preservativos e adoçantes/açúcares artificiais. Os agentes fosfato de sódio (mono, di e tri) não foram identificados na lista de aditivos permitida para o leite nos Estados Unidos. $O$ citrato de sódio, de acordo com o FDA, pode ser utilizado em leites como tampão e agente neutralizador em leites acidificados e fermentados.

Na Europa, a legislação EU n 1129/2011 (EUROPEAN UNION, 2011) aplicada a partir de 01 de junho de 2013, regulamenta os aditivos permitidos na categoria de leites UHT sem saborizantes. Os aditivos permitidos na Europa encontram-se listados na tabela 2. É relevante salientar que de acordo com a legislação vigente na Europa 
(EU1129/2011), o citrato de sódio é permitido apenas para o leite UHT de cabra. RaynalLjutovac, Massouras e Barbosa (2004) ao analisar a estabilidade térmica do leite de cabra de países como a França, Grécia e Portugal citam que o leite caprino possui menor estabilidade ao tratamento térmico quando comparado ao leite bovino. Wen Sun (2012) reporta que a susceptibilidade do leite de cabra à sedimentação é alta devido à quantidade elevada de íons de cálcio presentes neste alimento. Assim, recursos como a utilização de aditivos podem ser alternativas viáveis para melhorar a estabilidade térmica do produto.

Ao analisar as legislações para aditivos do Brasil, Europa e Estados Unidos da América é possível observar que a quantidade de aditivos empregados no Brasil em leites UHT é maior do que na Europa e Estados Unidos da América. Observa-se que, em relação à quantidade permitida, o Brasil e a Europa têm os mesmos limites permitidos para o citrato de sódio.

Comparando-se o leite nacional, americano e europeu, primeiramente, deve-se avaliar as características que influenciam na estabilidade térmica do leite, visto que o emprego de estabilizantes é justificado por conta da sedimentação de compostos do leite UHT o que promove uma série de transtornos para a indústria, pois compromete a eficiência dos trocadores de calor e paradas na linha de produção. Assim, os fatores que influenciam na estabilidade do leite são: $\mathrm{pH}$ (índices próximos a 6,7 promovem maior estabilidade térmica), alta contagem de células somáticas (indicam alta atividade de enzimas que atuam em proteólises e lipólises), estabilidade frente ao teste do alizarol exceto para o leite instável não ácido, saúde do rebanho, as condições higiênicosanitárias durante as etapas de produção, período de armazenamento, transporte, local e periodo de refrigeração para evitar que ocorram a multiplicação de psicotróficos (RODRIGUES, 2012; BRASIL; NICOLAU; SILVA, 2015).

É preciso considerar que a qualidade do leite cru, no Brasil, é deficiente. Esta situação é preocupante, visto que um produto que não apresenta características satisfatórias ou que ao longo da cadeia produtiva ocorreram falhas referentes aos prérequisitos básicos de boas práticas de fabricação, provavelmente, desencadeará problemas ao longo do processo de industrialização do produto, principalmente, no caso do leite UHT, durante a etapa de tratamento térmico (RODRIGUES, 2012). Assim sendo, a tabela 3 traz uma comparação das características do leite no Brasil, Estados Unidos da América e no Reino Unido. Ao analisar essa tabela, conclui-se que o Brasil está menos rigoroso em relação à qualidade do leite e que este fato compromete a industrialização do produto e a competitividade do mesmo em relação aos padrões internacionais.

Tabela 3. Características do leite no Brasil, Estados Unidos da América e Reino Unido.

\begin{tabular}{|c|c|c|c|c|}
\hline \multirow[b]{2}{*}{ Indicadores } & \multicolumn{2}{|c|}{ BRASIL } & \multirow[b]{2}{*}{$\begin{array}{l}\text { Estados } \\
\text { Unidos da } \\
\text { América }\end{array}$} & \multirow[b]{2}{*}{ Reino Unido } \\
\hline & $\begin{array}{c}\text { Clínica do } \\
\text { Leite }\end{array}$ & $\begin{array}{c}\text { Embrapa Gado } \\
\text { de Leite }\end{array}$ & & \\
\hline Gordura \% & 3,63 & 3,71 & 3,7 & 4,06 \\
\hline Proteína \% & 3,21 & 3,27 & 3,4 & 3,28 \\
\hline CBT (milUFC/mL) & 283 & 648 & 25 & 30 \\
\hline CCS (milUFC/mL) & 343 & 393 & 290 & 196 \\
\hline
\end{tabular}

Legenda: CBT - Contagem Bacteriana Total; CCS - Contagem de Células Somáticas.

Fonte: Carvalho, 2010. 
Ao realizar a comparação dos teores de gordura, de proteína e as quantidades de CBT e CCS no Brasil, Estados Unidos da América e Reino Unido constata-se que somente os Estados Unidos da América e o Reino Unido conseguem se enquadrar nos níveis de CBT propostos pelo MAPA na Instrução Normativa 62 de 2012 (MAPA, 2012), que preconiza que a quantidade de CBT deveria ser reduzida até $100 \mathrm{mil} \mathrm{UFC} / \mathrm{mL}$, até 2016 (CARVALHO, 2010). Enfatiza-se que a CBT está relacionada com a qualidade higiênica durante a ordenha, portanto, investimentos em boas práticas de fabricação seria uma alternativa para conseguir alcançar os padrões propostos na legislação. Destaca-se ainda, que não existem dados mais recentes para fazermos a comparação.

\section{Aditivos em Queijo tipo muçarela}

No Brasil, a portaria no 364 de 04 de setembro de 1997 (MAPA, 1997), preconiza que para a fabricação de queijo tipo Muçarela devem ser empregados os aditivos permitidos no Regulamento Técnico Geral de Identidade e Qualidade de Queijos, expressos na Portaria no 146 de 07 de março de 1996 (MAPA, 1996). A legislação brasileira ainda permite que seja empregado na produção de muçarela de muito alta umidade (m.a.u.) o aditivo Peróxido de Benzoila (máximo 20 mg/L de leite) e Dióxido de Titânio (segundo as Boas Práticas de Fabricação - BPF) e na produção de queijo de média ( $\mathrm{m}$. u) e alta umidade (a. u.) podem ser usados saborizantes e flavorizantes, exceto os aromas de queijo e creme. A tabela 4 informa os aditivos que podem ser utilizados na elaboração de queijo muçarela no Brasil.

Tabela 4. Aditivos permitidos para queijos.

\begin{tabular}{|c|c|c|c|}
\hline Nome & Função & Limite (Max/conc) & Tipo de queijo \\
\hline Ácido cítrico & Regulador de Acidez & BPF & m.a.u. \\
\hline Ácido láctico & Regulador de Acidez & BPF & m.a.u. \\
\hline Àcido acético & Regulador de Acidez & BPF & m.a.u. \\
\hline $\begin{array}{c}\text { Aroma Natural de } \\
\text { Defumado }\end{array}$ & Aromatizante & BPF & $\begin{array}{c}\text { m.a.u.; a.u.; m.u.; } \\
\text { b.u. }\end{array}$ \\
\hline $\begin{array}{c}\text { Aromatizantes (exceto } \\
\text { aroma de queijo e } \\
\text { creme) }\end{array}$ & Aromatizante & BPF & m.a.u. \\
\hline Nísina & Conservador & $12,5 \mathrm{mg} / \mathrm{kg}$ & $\begin{array}{c}\text { m.a.u.; a.u.; m.u.; } \\
\text { b.u. }\end{array}$ \\
\hline $\begin{array}{c}\text { Ácido sórbico e seus } \\
\text { sais de sódio, potássio } \\
\text { e cálcio }\end{array}$ & Conservador & $\begin{array}{c}1000 \text { mg/kg (em ácido } \\
\text { sórbico) }\end{array}$ & $\begin{array}{l}\text { m.a.u.; a.u.; m.u.; } \\
\text { b.u. }\end{array}$ \\
\hline $\begin{array}{c}\text { Nitrato de sódio ou } \\
\text { potássio (isolados ou } \\
\text { combinados) }\end{array}$ & Conservador & $\begin{array}{c}50 \mathrm{mg} / \mathrm{kg} \text { (em nitrato de } \\
\text { sódio) }\end{array}$ & m.u.; b.u. \\
\hline Lisozima & Conservador & $\begin{array}{c}20 \mathrm{mg} / \mathrm{L} \mathrm{de} \mathrm{leite} \\
1 \mathrm{mg} / \mathrm{dm}^{2}\end{array}$ & m.u.; b.u. \\
\hline Natamicina & Conservador & 5 mg/kg só na superficie. & m.a.u.b. \\
\hline $\begin{array}{l}\text { Carotenóides, } \\
\text { Naturais, beta } \\
\text { caroteno, bixina, nor } \\
\text { bixina, urucum, } \\
\text { annatto, rocu }\end{array}$ & Corante & $\begin{array}{c}10 \mathrm{mg} / \mathrm{kg} \text { de queijo (como } \\
\text { norbixina) }\end{array}$ & $\begin{array}{l}\text { m.a.u.; a.u.; m.u.; } \\
\text { b.u. }\end{array}$ \\
\hline $\begin{array}{l}\text { Clorofila, clorofilina, } \\
\text { clorofilina crúpica, sais }\end{array}$ & Corante & $\begin{array}{c}15 \text { mg/kg de queijo (em } \\
\text { clorofila) }\end{array}$ & a.u.; m.u.; b.u. \\
\hline
\end{tabular}


de sódio e potássio

\begin{tabular}{|c|c|c|c|}
\hline Curcuma, curcumina & Corante & BPF & $\begin{array}{c}\text { m.a.u.; a.u.; m.u.; } \\
\text { b.u. }\end{array}$ \\
\hline Carmim & Corante & BPF & m.a.u. \\
\hline $\begin{array}{l}\text { Betacaroteno Sintético } \\
\text { (idêntico ao natural) }\end{array}$ & Corante & $600 \mathrm{mg} / \mathrm{kg}$ de queijo & $\begin{array}{c}\text { m.a.u.; a.u.; m.u.; } \\
\text { b.u. }\end{array}$ \\
\hline Riboflavina & Corante & BPF & --- \\
\hline $\begin{array}{l}\text { Vermelho de } \\
\text { Beterraba }\end{array}$ & Corante & BPF & -- \\
\hline Peróxido de Benzoila & Corante & $20 \mathrm{mg} / \mathrm{L}$ de leite & a.u.; m.u.; b.u. \\
\hline Dióxido de Titânio & Corante & BPF & a.u.; m.u.; b.u. \\
\hline Carboximetilcelulose & $\begin{array}{l}\text { Espessante/ } \\
\text { Estabilizante }\end{array}$ & $5 \mathrm{~g} / \mathrm{kg}$ de queijo & m.a.u. \\
\hline Carragenina & $\begin{array}{l}\text { Espessante/ } \\
\text { Estabilizante }\end{array}$ & $5 \mathrm{~g} / \mathrm{kg}$ de queijo & m.a.u. \\
\hline Goma Guar & $\begin{array}{l}\text { Espessante/ } \\
\text { Estabilizante }\end{array}$ & $5 \mathrm{~g} / \mathrm{kg}$ de queijo & m.a.u. \\
\hline Goma de Algaroba & $\begin{array}{l}\text { Espessante/ } \\
\text { Estabilizante }\end{array}$ & $5 \mathrm{~g} / \mathrm{kg}$ de queijo & m.a.u. \\
\hline Goma Xantana & $\begin{array}{l}\text { Espessante/ } \\
\text { Estabilizante }\end{array}$ & $5 \mathrm{~g} / \mathrm{kg}$ de queijo & m.a.u. \\
\hline Goma Karaya & $\begin{array}{l}\text { Espessante/ } \\
\text { Estabilizante }\end{array}$ & $5 \mathrm{~g} / \mathrm{kg}$ de queijo & m.a.u. \\
\hline Goma Arábica & $\begin{array}{l}\text { Espessante/ } \\
\text { Estabilizante }\end{array}$ & $5 \mathrm{~g} / \mathrm{kg}$ de queijo & m.a.u. \\
\hline Agar & $\begin{array}{l}\text { Espessante/ } \\
\text { Estabilizante }\end{array}$ & $5 \mathrm{~g} / \mathrm{kg}$ de queijo & m.a.u. \\
\hline Ácido Algímico, seus & & & \\
\hline $\begin{array}{l}\text { sais de amônio, cálcio } \\
\text { e sódio, alginato de } \\
\text { propilenoglicol }\end{array}$ & $\begin{array}{l}\text { Espessante/ } \\
\text { Estabilizante }\end{array}$ & $5 \mathrm{~g} / \mathrm{kg}$ de queijo & m.a.u. \\
\hline $\begin{array}{l}\text { Pectina ou Pectina } \\
\text { Amidada }\end{array}$ & $\begin{array}{l}\text { Espessante/ } \\
\text { Estabilizante }\end{array}$ & $5 \mathrm{~g} / \mathrm{kg}$ de queijo & m.a.u. \\
\hline Alginato de Potássio & $\begin{array}{l}\text { Espessante / } \\
\text { Estabilizante }\end{array}$ & $500 \mathrm{mg} / \mathrm{kg}$ de queijo & m.a.u. \\
\hline Amido Modificado & $\begin{array}{l}\text { Espessante/ } \\
\text { Estabilizante }\end{array}$ & BPF & m.a.u. \\
\hline Lípases & Agente de Maturação & BPF & m.u.; b.u. \\
\hline Proteases & Agente de Maturação & BPF & b.u. \\
\hline
\end{tabular}

Observação: As siglas m.a.u., a.u, m.u., b.u. são abreviações referentes à muito alta umidade, alta umidade, media umidade e baixa umidade, respectivamente.

Fonte - MAPA, 1997; MAPA, 1996.

Para identificar os aditivos permitidos na elaboração de queijo tipo Muçarela nos Estados Unidos da América, foi realizada uma busca no portal de dados do FDA identificado como: Everything added to food in the United States (EAFUS, s.d.) mediante a inserção do código do produto do CFR: 133.155, 133.156, 133.157 e 133.158. A tabela 5 lista os aditivos para queijo tipo Muçarela nos Estados Unidos da América. Os antifúngicos podem ser empregados na formulação de queijos, portanto, o CFR 172 aprova o uso da Natamicina (Piramicina) para o consumo humano. O CFR 133.179 aborda os aditivos que podem ser utilizados para queijos pasteurizados e os corantes são mencionados no CFR 101.22 (EAFUS, s.d.). 
Tabela 5. Aditivos permitidos para queijos nos Estados Unidos da América, segundo o FDA.

Aditivo

\section{Cloreto de sódio \\ Cloreto de cálcio \\ Natamicina}

Ácido sórbico, sorbato de potássio, sorbato de sódio

Lecitina

Nisina

Quantidade (máxima)

$$
\begin{gathered}
0,02 \% \\
20 \mathrm{ppm} \\
0,2 \% \\
0,03 \% \\
250 \mathrm{ppm}
\end{gathered}
$$

$0,8 \%$

Gomas (Carboximetilcelulosa, xantana, guar, carragena, gelatina,

propilenoglicolalginato)

Fonte: (EAFUS, s.d.)

\begin{tabular}{|c|c|c|}
\hline Aditivos & Quantidade (máxima) & Código \\
\hline Ácido sórbico, sorbatos & $1000 \mathrm{mg} / \mathrm{kg}$ & E $200-203$ \\
\hline Ácido acético & Quantum satis & E260 \\
\hline Ácido lático & Quantum satis & E270 \\
\hline Ácido cítrico & Quantum satis & E330 \\
\hline Celulose & Quantum satis & E 460 \\
\hline Glucodeltalactona & Quantum satis & E 575 \\
\hline Corantes (Grupo III) & 150 ppm & $\begin{array}{c}\text { E } 100,102,120,122,129,131,132,133 \\
142,151,155,160 \mathrm{e}, 161 \mathrm{~b} .\end{array}$ \\
\hline
\end{tabular}

Na Europa, os aditivos para queijo tipo Muçarela foram identificados na categoria 16 (1.7.1) do banco de dados de aditivos na Europa, preconizados pela EU 1129/2011 (EUROPEAN UNION, 2011) e estão listados na tabela 6.

Tabela 6. Aditivos para queijo tipo Muçarela permitidos na Europa.

Fonte: EUROPEAN UNION, 2011.

A lista de aditivos para queijo tipo Muçarela é bastante diversificada em todas as localidades estudadas e permite a utilização de corantes, conservantes, aromatizantes, dentre outros. Gonçalves et.al. (2011) ao avaliar a ocorrência de nitratos e nitritos em queijos Minas Frescal, Muçarela, Parmesão e Prato identificou que é necessário um maior monitoramento de aditivos nestes produtos, visto que em queijos parmesão e prato os índices de nitrato estavam acima do permitido pela legislação. No queijo Minas Frescal foi detectada a presença deste conservante, a qual não era esperada por conta do consumo rápido do produto. Entretanto, ao analisar o queijo Muçarela a avaliação estava de acordo com a legislação. Destaca-se que, no Brasil, a Portaria 146/1996 (MAPA,1996) permite a utilização de nitrato de sódio e potássio em queijos de alta ou muito alta umidade com o limite de $50 \mathrm{mg} / \mathrm{kg}$. Já para nitritos, estabelece-se que este deve estar ausente, independente do teor de umidade do produto. Este autor comenta ainda que é necessário o emprego destes produtos para evitar que ocorram problemas como o estufamento do queijo, pois no Brasil para evitar defeitos oriundos do estufamento tardio em queijos são necessárias melhorias nos aspectos de higiene, investimentos em tecnologia e avaliação de eficiência de métodos alternativos que visem resolver os problemas tecnológicos na produção.

$\mathrm{Na}$ Europa, a legislação permite a adição de poucos aditivos alimentares em produtos lácteos. lammarino e Di Taranto (2013) citam que mesmo os aditivos mais utilizados na produção de alimentos como: ácido sórbico e nitratos; e os reguladores de 
acidez: ácido lático, ácido acético e fosfatos encontram algumas barreiras para serem utilizados na legislação europeia. Os nitratos podem ser empregados em queijos classificados como duros, semi-duros e semi-moles com dosagem estabelecida de 150 $\mathrm{mg} / \mathrm{kg}$, inclusive este teor é maior do que é preconizado na legislação brasileira.

Nos Estados Unidos da América, o FDA declara que os sais de nitratos não são considerados seguros e que, portanto, não devem ser incluídos na fabricação de produtos lácteos, incluindo queijos. Por meio do documento identificado como alerta de importações 12-12 elaborado pelo FDA, prevê-se que sejam detidos os produtos importados que contenham os sais de nitrato (251 e 252). Salienta-se que estes aditivos são liberados para derivados cárneos.

Ao analisar a lista de aditivos permitidos pelo Codex para queijo tipo Muçarela Codex Stan 262 (Codex Standart, 2006), observa-se que o nitrato não consta na lista. Segundo o Codex, o nitrato encontra-se na lista de aditivos permitidos para outros queijos Codex Stan 283 (Codex Standart, 1978) em quantidades de $50 \mathrm{mg} / \mathrm{kg}$, que é igual à quantidade preconizada pela legislação brasileira. $O$ ácido sórbico e os sorbatos são conservantes amplamente utilizados no Brasil, aproximadamente $11,15 \%$ dos alimentos comercializados no país e $49,42 \%$ e $16,88 \%$ para as categorias de leites/iogurtes e frios/laticinios, respectivamente conforme concluíram Silva e Oliveira (2015). O ácido sórbico é seguro para o consumo e não apresenta toxicidade e riscos à saúde dos consumidores, obedecendo a ingestão de $25 \mathrm{mg} / \mathrm{kg}$ (Revista Insumos, 2015).

Outro aspecto importante é a utilização do dióxido de titânio como corante. Esta substância é utilizada no Brasil, em quantidades que devem seguir as boas práticas de fabricação. Na Europa, é empregado em produtos lácteos fermentados: como iogurtes e nos Estados Unidos da América pode ser empregado em alimentos desde que não exceda $1 \%$ do peso do produto final. Souza e Rodrigues (2011) ao analisarem a presença de corantes em laticínios, concluíram que apesar de o dióxido de titânio ser o corante artificial mais utilizado nos produtos analisados, no setor de queijos foram empregados apenas corantes naturais. A preocupação com o dióxido de titânio está relacionada com lesões e processos intestinais inflamatórios. Tais fatos motivaram o projeto de Lei 1370/11 (PL 1370, 2011) que solicita que esta substância seja proibida em produtos alimentícios e em cosméticos. Esta lei está em processo de avaliação no setor legislativo brasileiro.

Assim, propõe-se que sejam estudadas medidas que reduzam a utilização de corantes artificiais em todas as categorias de produtos lácteos, visto os corantes naturais apresentam características atrativas para a indústria de alimentos, como: a capacidade de tingimento e apelos funcionais como, por exemplo as antocianinas presentes em cascas de jabuticabas (Constant et al., 2002; Silva et. al. 2010). Estudos para analisar a viabilidade do emprego destas substâncias em detrimento às artificiais devem ser realizados, principalmente, quanto aos aspectos ligados à estabilidade térmica, presença de luz e $\mathrm{pH}$ que ainda são fatores que podem limitar o emprego de alguns corantes naturais. Afinal, os consumidores estão mais atentos e exigentes, procurando produtos que contribuam para nutrição, bem-estar e a promoção da qualidade de vida.

\section{Aditivos em logurtes}

No Brasil, a Instrução Normativa n 46/2007 (MAPA, 2007) estabelece a lista de aditivos permitidos para serem utilizados na formulação de iogurtes. A legislação cita que para produtos com preparados de fruta ou agregado de frutas, podem ser utilizados ácido sórbico e seus sais de sódio, potássio e cálcio em uma concentração máxima de 300 $\mathrm{mg} / \mathrm{kg}$ no produto final (expressos em ácido sórbico). A tabela 7 apresenta os aditivos permitidos pela legislação brasileira. 
Tabela 7 - Aditivos permitidos para a fabricação de iogurtes no Brasil

INS

Aditivo

Quantidade máxima no produto final

\begin{tabular}{|c|c|c|}
\hline \multicolumn{3}{|c|}{ Corantes $(\mathrm{mg} / \mathrm{Kg})$} \\
\hline 100 & Cúrcuma ou curcumina & 80 \\
\hline $101 \mathrm{i}$ & Riboflavina & 30 \\
\hline $101 \mathrm{ii}$ & Riboflavina 5' - Fosfato de sódio & 30 \\
\hline 110 & Amarelo ocaso FCF Amarelo Sunset & 50 \\
\hline 120 & Carmim, Ácido Carminico, Cochonilha & 100 ác. carmínico \\
\hline 122 & Azorrubina & 50 \\
\hline 124 & Vermelho Ponceau 4R & 50 \\
\hline 129 & Vermelho 40, allura & 50 \\
\hline 131 & Azul patente V & 50 \\
\hline 132 & Indigotina, Carmim Indigo & 50 \\
\hline 133 & Azul Brilhante FCF & 50 \\
\hline $140 \mathrm{i}$ & Clorofila & q.s. \\
\hline $141 \mathrm{i}$ & Clorofila cúprica & 50 \\
\hline $141 \mathrm{ii}$ & Clorofilina cúprica & 50 \\
\hline 143 & Verde indelevel, verde rápido fast & 50 \\
\hline $150 a$ & Caramelo I simples & q.s. \\
\hline $150 \mathrm{~b}$ & Caramelo II processo sulfito cáustico & q.s. \\
\hline $150 c$ & Caramelo III - processo amônia & 500 \\
\hline $150 d$ & Caramelo IV - sulfito amônia & 500 \\
\hline 160ai & Beta caroteno (idêntico ao natural) & 50 \\
\hline 160aii & Carotenoides, extratos naturais & 50 \\
\hline $160 \mathrm{~b}$ & Annato, bixina, norbixina, urucum & 9,5 \\
\hline \multicolumn{3}{|c|}{$\begin{array}{ll}\text { Espessante/Estabilizante }(\mathrm{g} / \mathrm{Kg})\end{array}$} \\
\hline 162 & Beterraba & q.s. \\
\hline 407 & $\begin{array}{l}\text { Carragenina e seus sais de sódio e potássio } \\
\text { (inclusive furcelarana), musgo irlandês }\end{array}$ & 5 isolados ou combinados \\
\hline 412 & Goma Guar & \\
\hline 410 & $\begin{array}{l}\text { Goma Alfarroba, Goma Jataí, Goma Garrofin, } \\
\text { Goma Caroba }\end{array}$ & \\
\hline 415 & Goma Xantana, Goma Xantan, Goma de Xantana & \\
\hline 416 & Goma Karaya, Goma Stercúlia, Goma Caráia & \\
\hline 414 & Goma Arábica, Goma Acácia & \\
\hline 413 & Goma Tragacanto, Goma Adragante, Tragacanto & \\
\hline 418 & Goma Gellan & \\
\hline 425 & Goma Konjac & \\
\hline 406 & Agar & \\
\hline 400 & Ácido Algínico & \\
\hline 401 & Alginato de Sódio & \\
\hline 402 & Alginato de Potássio & \\
\hline 403 & Alginato de Amônio & \\
\hline 404 & Alginato de Cálcio & \\
\hline 405 & Alginato de propileno glicol & \\
\hline 440 & Pectinas e pectina amidada & \\
\hline ----- & Gelatina & 10 isolados ou combinados \\
\hline
\end{tabular}

Acidulante $(\mathrm{g} / \mathrm{Kg})$

$330 \quad$ Ácido Cítrico

270 Ácido Láctico

296 Ácido Málico 
Revista Brasileira de Ciencia, Tecnołogia e Inovaçào

334 Ácido Tartárico

5

Conservador $(\mathrm{mg} / \mathrm{kg})$

200 Ácido Sórbico

201 Sorbato de sódio

202 Sorbato de potássio

300 expresso em ácido sórbico

203 Sorbato de cálcio

235 Natamicina

Fonte: MAPA, 2007.

Nos Estados Unidos da América, os aditivos permitidos para fabricação de iogurtes foram identificados na base de dados (EAFUS, s.d.), do FDA. Os códigos dos produtos verificados foram: 131.200, 131.203 e 131.206. A adição de corantes deve seguir o que manda o CFR 101.30 podendo ser naturais ou artificiais. Vale salientar que a exigência dos consumidores tem aumentado, portanto, apesar dos corantes artificiais serem mais baratos, os clientes preferem os corantes naturais (Chandan, Kilara, 2013). Em relação aos aromas o mais empregado é o de baunilha que deve ser orientado pelo CFR 169, mas podem ser utilizados frutas, xaropes e preparados de frutas. Na categoria de acidulantes, é permitido o emprego de ácido cítrico e málico. Na tabela 8 encontra-se a lista completa dos aditivos permitidos nos Estados Unidos da América.

Tabela 8. Aditivos permitidos para iogurtes nos Estados Unidos da América.

\begin{tabular}{ll}
\hline Aditivo & Quantidade (máxima) \\
\hline Xarope de milho & G.M.P. \\
Açúcar invertido & G.M.P. \\
Xarope de açúcar invertido & G.M.P. \\
Lactoalbumina/ Lactose/ Maltose &.--- \\
Xarope de malte & G.M.P \\
Sacarose & G.M.P \\
Vitamina A & 2000 I.U/ $946 \mathrm{~mL}$ \\
Vitamina D & 400 I.U. / $946 \mathrm{~mL}$ \\
Soro de Leite & G.M.P \\
Soro de Leite parcialmente desmineralizado & parcialmente \\
deslactosado & G.M.P \\
Estabilizante WPC/ MPC & $0,7-2,0 \%$ \\
Amido modificado de mandioeca e milho & $0,8-2,0 \%$ \\
Gelatina (225/250) & $0,1-0,5 \%$ \\
Agar & $0,25-0,7 \%$ \\
Pecitina baixa metoxidade & $0,08-0,20 \%$ \\
Goma de Alfarroba & $0,3-0,5 \%$ \\
Goma Xantana & $0,01-0,05 \%$ \\
\hline
\end{tabular}

Fonte: EAFUS, s.d.

Legenda: GMP - Good Manufacturing Practices.

$\mathrm{Na}$ Europa, os aditivos para iogurte foram identificados na categoria 16 (1.4) do banco de dados de aditivos na Europa, preconizados pela EU 1129/2011 (EUROPEAN UNION, 2011) . A lista completa dos aditivos permitidos na Europa encontra-se na tabela 9. A lista de ingredientes de iogurtes é bastante diversificada incluindo aditivos de diversas categorias, por exemplo: estabilizantes, corantes, acidulantes e conservantes, conforme listadas no Codex 243-2003 (CODEX STANDART, 2003). 
Tabela 9. Ingredientes permitidos para iogurte na Europa.

\section{Aditivos}

\section{Aditivos}

Aditivos do grupo I

Corantes do grupo II

Corantes do grupo III

Poliois

Amarelo de quinoleína

Amarelo/ Laranja Sunset

Ponceau 4R, vermelho cochonilha A

Anato, bixina, norbixina

Licopeno

Ácido fosfórico - fosfatos - di - tri- e polifosfatos

Ácido succínico

Goma Karaya

Goma Acácia

Polissorbatos

Ésteres de sacarose de ácidos gordos, sucroglicéridos

Talco, ésteres de poliglicerideo,

Ésteres de propanodiol

Esteriolactatos de sódio e cálcio

Esteriltartarato

Esteres de sorbitol

Acessulfame de Potássio

Aspartame

Ácido ciclamico e seus sais de sódio e potássio

Sacarina e seus sais de sódio e potássio

Sucralose

Taumatina

Neoespiridina
Quantidade (máxima)

$1000 \mathrm{mg} / \mathrm{kg}$

Quantum satis

Quantum satis

Quantum satis

Quantum satis

Quantum satis

150 ppm

$10 \mathrm{mg} / \mathrm{L}$

$30 \mathrm{mg} / \mathrm{L}$

$3000 \mathrm{mg} / \mathrm{L}$

$6000 \mathrm{mg} / \mathrm{L}$

$6000 \mathrm{mg} / \mathrm{L}$

$2500 \mathrm{mg} / \mathrm{L}$

$1000 \mathrm{mg} / \mathrm{L}$

$5000 \mathrm{mg} / \mathrm{L}$

$2000 \mathrm{mg} / \mathrm{L}$

$5000 \mathrm{mg} / \mathrm{L}$

$5000 \mathrm{mg} / \mathrm{L}$

$5000 \mathrm{mg} / \mathrm{L}$

$5000 \mathrm{mg} / \mathrm{L}$

$350 \mathrm{mg} / \mathrm{L}$ apenas para alimentos com o valor calórico reduzido ou sem açúcar $1000 \mathrm{mg} / \mathrm{L}$ apenas para alimentos com o valor calórico reduzido ou sem açúcar $250 \mathrm{mg} / \mathrm{L}$, apenas para alimentos com o valor calórico reduzido ou sem açúcar $100 \mathrm{mg} / \mathrm{L}$, apenas para alimentos com o valor calórico reduzido ou sem açúcar $400 \mathrm{mg} / \mathrm{L}$, apenas para alimentos com o valor calórico reduzido ou sem açúcar

$5 \mathrm{mg} / \mathrm{L}$, intesificador de aroma/sabor

$50 \mathrm{mg} / \mathrm{L}$, apenas para alimentos com o valor calórico reduzido ou sem açúcar
Código

E 200 - 203

E260

E270

E330

E 104

E 110

E 124

E 160 b

E160 d

E 338 - 341, E 343 e E 450 452

E 363

E 4416

E427

E $432-436$

E $473-474$

E 475

E477

E $481-482$

E 483

E 491 - 495

E 950

E 951

E 952

E 954

E955

E 957

E 959 
Neotame

Sal de aspartame e acessulfame

Glicosideos de estaviol

Advantame
$32 \mathrm{mg} / \mathrm{L}$, apenas para alimentos com o valor calórico reduzido ou sem açúcar $350 \mathrm{mg} / \mathrm{L}$, apenas para alimentos com o valor calórico reduzido ou sem açúcar $100 \mathrm{mg} / \mathrm{L}$, apenas para alimentos com o valor calórico reduzido ou sem açúcar $10 \mathrm{mg} / \mathrm{L}$, apenas para alimentos com o valor calórico reduzido ou sem açúcar,
E 961

E 962

E 960

E 969

Legenda: Quantum satis - quantidade necessária;

Fonte: EUROPEAN COMISSION, 2011.

Comparando-se as legislações vigentes nas três localidades estudadas, propõese que no Brasil a questão da utilização de aditivos naturais como corantes e aromatizantes seja mais bem difundida e seguida pelas empresas, pois é tendência que os consumidores anseiem por produtos com menos substâncias sintéticas, além de algumas pessoas desenvolverem reações adversas e alergias. Segundo a Brasil Food Trends a categoria de iogurtes, com $32 \%$, é a que mais estimula o desejo de compra dos consumidores ao lançar um novo produto quando comparado com demais produtos alimentícios, como: bolachas, sucos, chocolates, queijos, dentre outros. Sob este aspecto, observa-se que este é um potencial mercado em expansão e que atrai o desejo dos consumidores inovadores (Brasil Food Trends, s.d.).

Gallina (2013) afirma que queijos e iogurtes são os produtos mais versáteis em termos de inovação e que neste aspecto a formulação apresenta $78 \%$ de possibilidades para modificações, quando comparados com embalagens, tecnologia e posicionamento no mercado. As possibilidades para alterar a formulação dos iogurtes seguem critérios de nutrição funcional, diversificação da matéria prima e produtos orgânicos. Afinal, já é uma realidade no cotidiano de europeus e norte-americanos a disponibilidade de iogurtes especiais exclusivamente para crianças e bebês fabricados com ingredientes específicos, normalmente, orgânicos e sem adição de produtos sintéticos, fato este ainda não evidenciado no cotidiano dos brasileiros.

Assim, investimentos na melhoria da qualidade dos produtos brasileiros, emprego de ingredientes naturais, orgânicos, funcionais e sabores exóticos são alternativas atraentes para os consumidores que associam o consumo de iogurtes à alimentação saudável. Portanto, sugere-se rever alguns ingredientes vislumbrando a possibilidade de substituição destes por componentes que possam agregar valores nutricionais ao iogurte.

\section{CONCLUSÕES}

A partir desse estudo, é perceptível que os Estados Unidos da América e a Europa são localidades em que o panorama do setor lácteo já passou pela fase de implantação e possuem bem alicerçadas as estruturas básicas para o bom andamento da produção - desde a obtenção da matéria prima até o plano de gerenciamento de crises do sistema. Assim, nessas localidades podem ser desenvolvidas e executadas diretrizes mais focadas ao gerenciamento e expansão do setor em novos mercados, além de atuar na melhoria contínua para que o setor lácteo se mantenha em ascensão.

Apesar de ainda não estar no mesmo patamar, o Brasil está direcionando suas atividades para fortalecer os produtores de leite e laticínios, com o intuito de disponibilizar aos consumidores produtos de excelência em qualidade e segurança alimentar não somente para o mercado interno, mas também para ampliar os horizontes de comercialização em outros países. Entretanto, será imprescindível que os elos da cadeia produtiva (governo, empresas e produtores) estejam alinhados e com todos os recursos disponibilizados para 
execução de um trabalho edificante para a consolidação do mercado de lácteos no Brasil e no ranking internacional.

\section{AGRADECIMENTOS}

Os autores agradecem à FAPEMIG, CNPq e CAPES.

\section{REFERÊNCIAS}

$A B L V$. Leite longa vida preserva qualidades naturais do alimento sem o uso de conservantes, 2008. Disponível em:

<http://www.ablv.org.br/implistcontentint.aspx?id=523\&area=impnot\#sthash.KJGytuna.dpuf>. Acesso em: 18 nov. 2018.

ALVES, P.S.T. Teores de sódio e cálcio em leites UHT comercializados em Brasília, DF. Trabalho de Conclusão de Curso, Departamento de Nutrição. Universidade de Brasília, Brasília - DF, 2014.

ANVISA, Portaria - 540 de 27/10/1997. Disponível em:

http://portal.anvisa.gov.br/documents/33916/391619/PORTARIA_540_1997.pdf/3c55fd22d503-4570-a98b-30e63d85bdad. Acesso em: 18 de nov. 2018.

ANVISA, Resolução - 259 de 20/09/2002. Disponível em: http://www.organicsnet.com.br/wp-content/uploads/2015/12/ANVISA-NormasRotulagem.pdf. Acesso em: 18 de nov. 2018.

AUN, M.V. et al. Aditivos em Alimentos. Revista Brasileira de Alergia e Imunopatologia, v. 34, n.5, p. 177-186, 2011.

BRASIL FOOD TRENDS. Pesquisa Nacional Fiesp/IBOPE sobre o perfil do consumo de alimentos no Brasil. Disponível em: www.abic.com.br/media/EST_PESQFoodTrendsl.pdf. Acesso em: 18 de nov. 2018.

BRASIL, R.B; NICOLAU, E. S.; SILVA, M.A.P. Leite instável não ácido: fatores que afetam a estabilidade do leite. Ciência Animal, v.25, n. 4, p.15-26, 2015.

BRASIL. Ministério da Saúde. Agência Nacional de Vigilância Sanitária. Portaria $\mathbf{n}^{\circ} \mathbf{5 4 0}$ de 27 outubro de 1997. Aprova o Regulamento Técnico: Aditivos Alimentares definições, classificação e emprego). Disponível em:

http://portal.anvisa.gov.br/wps/wcm/connect/d1b6da0047457b4d880fdc3fbc4c6735/PORT ARIA_540_1997.pdf?MOD=AJPERES. Acesso em 18 de nov. 2018.

CANADIAN DAIRY INFORMATION CENTRE. Global milk consumption. Disponível em: http://www.dairyinfo.gc.ca/index_e.php?s1=dff-fcil\&s2=cons\&s3=consglo\&s4=tm-lt.

Acesso em 18 de nov. 2018. 
CARVALHO, G.R. A indústria de laticínios no Brasil: passado, presente e futuro. Embrapa Gado leite, v.102, p.1-12, 2010.

CODEX STANDART, 1978. Disponível em: http://www.fao.org/fao-whocodexalimentarius/shproxy/fr/?Ink=1\&url=https \%253A\%252F\%252Fworkspace.fao.org\%252Fsites\%252Fcodex $\% 252 F S t a n d a r d s \% 252 F C O D E X \% 2 B S T A N \% 2 B 283-1978 \% 252 F C X S$ 283e.pdf. Acesso em: 18 de nov. 2018.

CODEX STANDART, 2003. Disponível em:

file:///C:/Users/User/Downloads/CXS_243e.pdf. Acesso em: 18 de nov. 2018.

CODEX STANDART, 2006. Disponível em:

file:///C:/Users/User/Downloads/CXS_262e.pdf. Acesso em: 18 de nov. 2018.

CONSTANT, P.B.L.et al. Corantes Alimentícios. B.CEPPA, v. 20, n. 2, p.203-220, 2002.

DOMARESKI, J.L. et al. Avaliação físico-química e microbiológica do leite UHT comercializado em três países do Mercosul (Brasil, Argentina e Paraguai). ALAN, v. 60, n. 3, p. 261-269, 2010.

DSM FOOD SPECIALTIES. Dairy global insight series: patterns in yogurt consumption. Disponível em: http://www.machineryworld.co.uk/pdfs/dsm-yogurt-trendsconsumption-patterns.pdf. Acesso em 18 de nov. 2018.

EAFUS. Disponível em:

https://www.fda.gov/food/ingredientspackaginglabeling/foodadditivesingredients/ucm11532 6.htm. Acesso em: 18 de nov. 2018.

EUROPEAN UNION, Regulamento 1129 de 11/112011. Disponível em: https://publications.europa.eu/pt/publication-detail/-/publication/d825de4c-0061-429c8e72-60b800cf41b3/language-pt. Acesso em: 18 de nov. 2018.

GALLINA, D.A. Inovações na área de leites fermentados, 2013 Disponível em: www.ital.sp.gov.br/tecnolat/anais/.../Darlila\%20Gallina_ITAL.pdf. Acesso em 18 de nov. 2018.

GIESEL, T. Análise da rotulagem do leite integral UHT comercializado no Distrito Federal. Brasília, 2009, Monografia (Especialização Lato sensu em Vigilância Sanitária e Controle de Qualidade de Alimentos). Universidade Castelo Branco.

GONCALVES, J. F. et al. Ocorrência de nitratos e nitritos em queijos Minas Frescal, Mussarela, Parmesão e Prato. Rev. Inst. Adolfo Lutz, São Paulo, v. 70, n. 2, jun. 2011.

GRIZOTTO, R.K. et al. Estudo da vida-de-prateleira de fruta estruturada e desidratada obtida de polpa concentrada de mamão. Ciência e Tecnologia de Alimentos, v. 26, n. 3, p. 709-714, 2006. 
IAMMARINNO, M.; DI TARANTO, A. Development and Validation of an Ion Chromatography Method for the Simultaneous Determination of Seven Food Additives in Cheeses. Journal of Analytical Sciences, Methods and Instrumentation, v. 3, p. 3037, 2013.

MAPA, Instrução Normativa - 146 de 07/03/1996. Disponível em: https://www.defesa.agricultura.sp.gov.br/legislacoes/portaria-mapa-146-de-07-031996,669.html. Acesso em: 18 de nov. 2018.

MAPA, Instrução Normativa - 46 de 26/10/2007. Disponível em:

http://www.cidasc.sc.gov.br/inspecao/files/2012/08/instru\%C3\%87\%C3\%83o-normativan\%C2\%BA-46-de-23-de-outubro-de-2007.pdf. Acesso em: 18 de nov. 2018.

MAPA, Instrução Normativa - 51 de 18/09/2002. Disponível em: https://www.defesa.agricultura.sp.gov.br/legislacoes/instrucao-normativa-51-de-18-092002,654.html. Acesso em:18 de nov. 2018.

MAPA, Instrução Normativa - 62 de 01/01/2012. Disponível em: https://www.apcbrh.com.br/files/IN62.pdf. Acesso em: 18 de nov. 2018.

MAPA, Portaria - 364 de 04/09/1997. Disponível em:

https://www.defesa.agricultura.sp.gov.br/legislacoes/portaria-ma-364-de-04-091997,680.html. Acesso em: 18 de nov. 2018.

MAPA, Portaria - 370 de 04/09/1997. Disponível em: http://www.lex.com.br/doc_11361_PORTARIA_N_370_DE_4_DE_SETEMBRO_DE_1997. Acesso em 18 de nov. 2018.

MERCOSUL, Resolução - 135 de 1/1/1997. Disponível em: http://www.puntofocal.gov.ar/doc/r_gmc_135-96.pdf. Acesso em: 18 de nov. 2018.

PEREIRA, A.C.S; MOURA, S.M.; CONSTANT, P.B.L.. Alergia alimentar: sistema imunológico e principais alimentos envolvidos. Semina: Ciências Biológicas e da Saúde, v. 29, n. 2, p. 189-200, 2008.

PL, Projeto de Lei 1370 de 17/05/2011. Disponível em: http://www.camara.gov.br/proposicoesWeb/fichadetramitacao?idProposicao $=502584$. Acesso em: 18 de nov. 2018.

RAYNAL-LJUTOVAC, K.; MASSOURAS, T.; BARBOSA, M. Goats milk and heat treatments. South African Journal of Animal Science, v.34, p.173-175, 2004.

REVISTA INSUMOS. Os sorbatos na conservação de alimentos. Revista Insumos, v.118, p. 26 - 31, 2015.

RODRIGUES, E. K. F.R. Alterações nas propriedades físico-químicas do leite esterilizado adicionado de estabilizantes durante a estocagem. Montes Claros, 2012, Dissertação Universidade Federal de Minas Gerais. 
SILVA, A.I.D. et al. Produção de iogurte. Porto, 2010.

SILVA, A.S.; OLIVEIRA, F.C. Frequência do uso de conservantes em alimentos comercializados no Brasil. $5^{\circ}$ Simpósio de Segurança Alimentar - Alimentação e Saúde, Bento Gonçalves, 2015.

SOUZA, I.S.; RODRIGUES, L.G. Análise comparativa entre rotulagem nutricional e tabelas de composição de leite e derivados comercializados no estado do Rio de Janeiro. $11^{\circ}$ CONGRESSO DA SBAN, 2011,Fortaleza: Sociedade Brasileira de Alimentação e Nutrição, 2011.

USDA, 24/10/2012. Disponível em:

https://gain.fas.usda.gov/Recent\%20GAIN\%20Publications/Thai\%20FDA\%20Revising\%2 0Standards $\% 20$ and $\% 20$ Labeling $\% 20 f o r \% 20$ Cow $\%$ E2\%80\%99s\%20Milk\%20Products_Ba ngkok_Thailand_10-24-2012.pdf. Acesso em: 18 de nov. 2018.

WEN SUN, D. Thermal Food Processing: New Technologies and Quality Issues. New City, 2012.

Recebido em: 23//11/2018

Aprovado em: 06/05/2019 